\title{
P-34
}

\section{Characterization of Agarwood (Aquilaria Malaccensis) Incense by Solid Phase Microextraction TechniquE}

\author{
Mastura I, Tajuddin SN, Yusoff MM
}

Faculty of Industrial Sciences and Technology, University Malaysia Pahang, Lebuhraya Tun Razak, 26300 Gambang, Pahang, Malaysia

The aim of this study was to investigate the incense smoke and headspace volatile compounds of lower grade, higher grade and commercial grade incense of agarwood (Aquilaria malaccensis). Two methods of extraction were used, viz., incense smoke trapped from burning samples and volatile headspace. Solid phase microextraction (SPME) was used followed by gas chromatography (GC) in order to extract and analyse volatile compounds. A divinylbenzene-carboxen-polydimethylsiloxane (DVB-CAR-PDMS) 50/30 $\mu \mathrm{m}$ fiber was chosen. Total of compounds identified in incense smoke for low grade was 53 compounds, 55 compounds in high grade and 56 compounds in commercial incense. On the contrary, for the volatile headspace, total of 15 compounds were found in low grade, 50 compounds in high grade and 44 compounds in commercial incense. From the results, it showed that major compounds were present in incense smoke were epoxybulnesene, norketoagarofuran and agarospirol. Conversely, caryophellene oxide, $\alpha$-elemol and nor-ketoagarofuran were major compounds present in volatile headspace. It can deduce that major compounds present were oxygenated sesquiterpenes.

\section{ACKNOWLEDGEMENTS}

The authors gratefully acknowledge grant RDU 110388 of Universiti Malaysia Pahang and Faculty of Industrial Science and Technology. 